\title{
Multicentric sebaceous gland carcinoma of the lid?
}

\author{
Hubertus von Below, Geoffrey E Rose, Alison C E McCartney, John E Wright
}

Sebaceous gland carcinomas are lid tumours of high malignancy. A 66-year-old woman is presented, in whom herpetic disciform keratitis was prolonged by lagophthalmos due to sebaceous carcinoma of the lids. The tumour was multicentric, with one focus in the upper lid and another focus in the lower lid; the possibility of spread across a previously performed tarsorraphy is discussed and opposed to a recent hypothesis dealing with malignant cell growth.

Moorfields Eye Hospital,

London

$\mathrm{H}$ von Below

G E Rose

J E Wright

Institute of

Ophthalmology, London

A C E McCartney

Correspondence to:

Mr G E Rose, Orbital Clinic/

Adnexal Service, Moorfields

Eye Hospital, City Road,

London ECIV 2PD.

Accepted for publication

is July 1993

\section{Case report}

A 66-year-old woman was referred to the orbital clinic at Moorfields Eye Hospital with a painless, red, hard, and immobile lid mass.

She had a 16 month history of herpetic stromal keratitis in the same eye, which had been treated with topical dexamethasone, acyclovir, and (because of persistence of the keratitis) a central tarsorraphy had been performed 6 months before referral. At that time a right superotemporal orbital 'cyst' was noted and a computed tomogram showed a soft tissue mass, of mixed attenuation, situated superolaterally in the right orbit (Fig 1); the mass had been presumed inflammatory in origin. Left ocular examination was normal.
When first seen at Moorfields Eye Hospital, she had two large masses situated superotem-

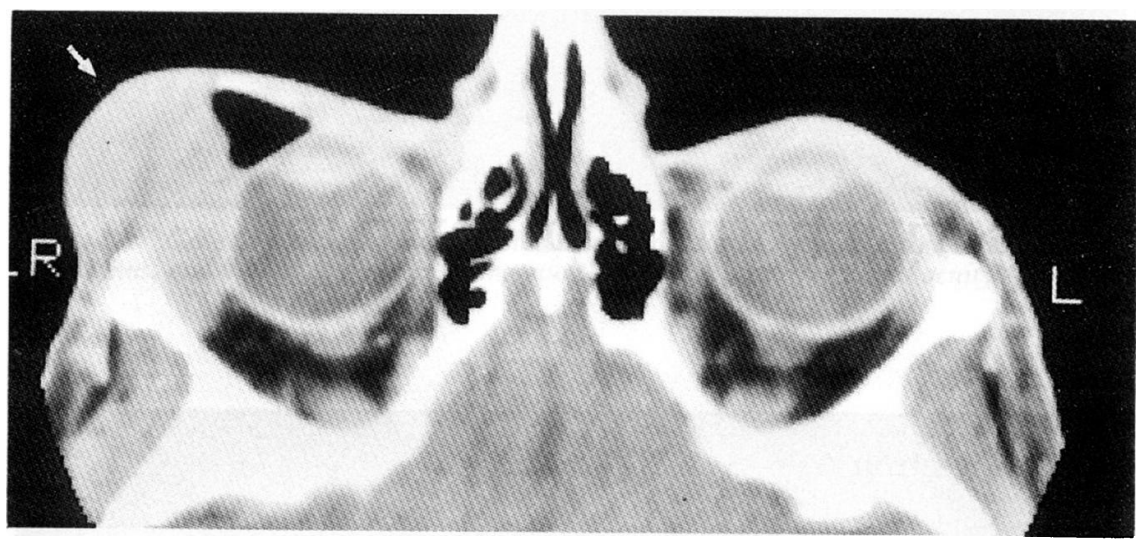

Figure 1 Computed tomogram of a 66-year-old woman with a sebaceous carcinoma of the right upper and lower eyelids (arrow).

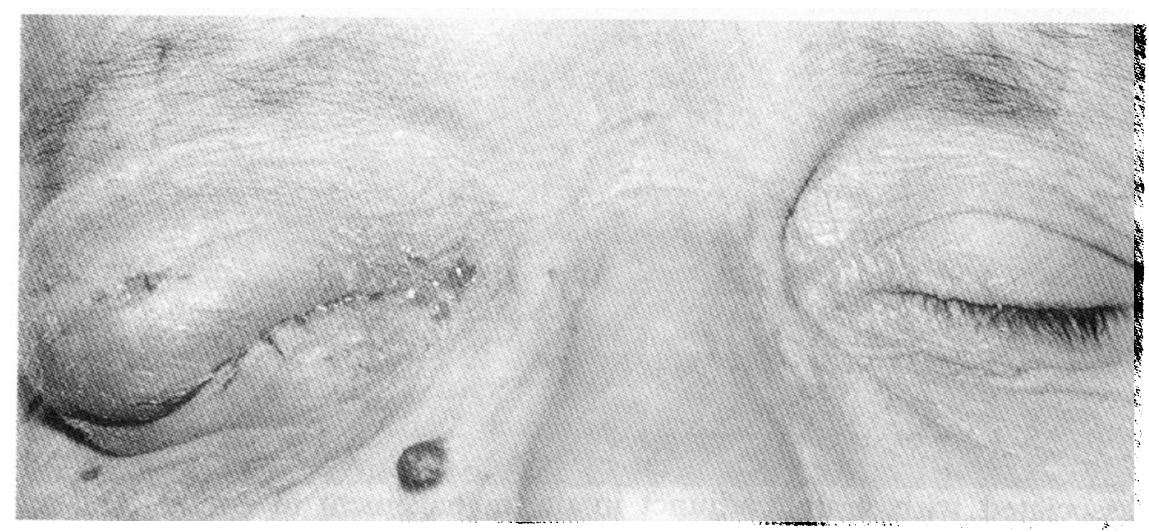

Figure 2 Patient before exenteration. A tarsorrhaphy had been performed for persistent herpetic keratitis 6 months before referral. porally and inferiorly in the right orbit; the masses precluded an eye examination (Fig 2). Chest $x$ ray was normal and haematological tests were unremarkable. Biopsy of the masses in the right upper and lower eyelids showed cells with lipid-containing vacuoles, compatible with sebaceous gland carcinoma (Fig 3).

A lid-sacrificing exenteration was performed and macroscopic sectioning suggested a multicentric origin for the carcinoma. On histology the tumour cells were, however, uniformly distributed within the upper and lower eyelid, but sparing the lacrimal drainage system. The corneal stromal scar was infiltrated with some lymphocytes and compatible with a mildly active chronic herpetic keratitis. A right preauricular lymph node was palpable and fine needle biopsy of the node demonstrated metastatic tumour, which required an en bloc dissection of the right involved cervical lymphatics and external radiotherapy. The patient is, at 9 months following her exenteration, alive without evidence of further metastatic disease.

\section{Comment}

Sebaceous cell carcinomas arise in sebaceous material secreting glands and are known to be occasionally multicentric. ${ }^{12}$ In the present case, the tarsorraphy might have contributed to the spread of tumour between the upper and lower eyelids. The chronic persistence of herpetic disciform keratitis, which should have responded rapidly to the topical steroids given before referral, suggests that the immune status and reactivity of the ocular surface might have been influenced by pagetoid (intraepithelial) spread of sebaceous carcinoma cells. It is also likely that the keratitis was exacerbated by lagophthalmos due to the invasive sebaceous carcinoma in the eyelids.

Meibomian gland or sebaceous carcinomas are commonly misdiagnosed as conjunctivitis, blepharitis, recurrent chalazia, basal cell carcinoma, cutaneous horn, or other lid tumours ${ }^{2-6}$; the diagnosis should always be considered early in patients with persistent adnexal disease. MuirTorre syndrome, ${ }^{78}$ with visceral malignancy, should be excluded and was not present in our patient. Radical surgery is generally recommended $^{9}$ for sebaceous carcinoma of the eyelids, although about $20 \%$ of such patients may die from metastatic disease. ${ }^{10} \mathrm{Lymph}$ node involvement, if present, should be assessed by fine needle biopsy, as open biopsy of nodes is thought to disseminate tumour cells and is, therefore, contraindicated. When aspiration biopsy is positive for malignant cells, en bloc resection of the cervical lymphatics may be indicated (as in our patient), although the value of postoperative irradiation and chemotherapy is probably limited. ${ }^{1011}$ 


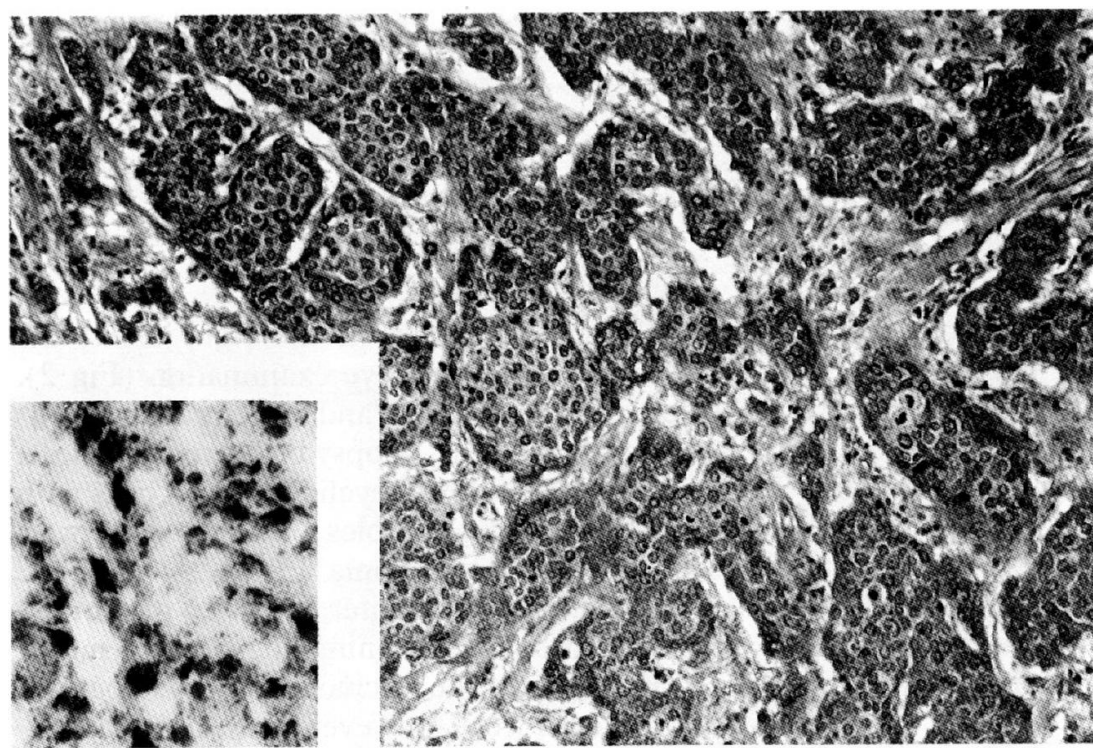

Figure 3 Sebaceous gland carcinoma of the upper right eyelid (haematoxylin and eosin, $\times 150)$. Inset: Histology of the masses in the right upper and lower eyelids showed cells with vacuoles containing lipid, compatible with sebaceous gland carcinoma (oil red $O, \times 490$ ).

However even if a multicentric sebaceous gland carcinoma could be excluded in our patient, this entity does probably exist. ${ }^{12}$ There are currently no explanations available for multicentric malignant cell growth. Only recently we became aware of a new concept for malignant cell growth. ${ }^{12}$ Genes may generate a determined number of cell divisions with subsequent inevita- ble death. If the death gene is defective, the cells will never stop growing. One defective death gene could be responsible for more than one cell line and thus explain multicentric malignant growth. Manipulation of inactive death gene might play a role in future research projects aiming at more effective treatment for cancer.

Hubertus von Below is supported by the Dr Mildred Scheel Foundation.

1 Boniuk M, Zimmerman LE. Sebaceous carcinoma of the eyelid, eyebrow, caruncle and orbit. Trans Am Acad Ophthalmol Otolaryngol 1968; 72: 619-42.

2 Cavanagh H, Green W, Goldberg H. Multicentric sebaceous adenocarcinoma of the meibomian gland. Am $\mathcal{F}$ Ophthalmol $1974 ; 77: 326-33$.

3 Lober CW, Fenske NA. Basal cell, squamous cell, and sebacious gland carcinomas of the periorbital region. f Am Acad Dermatol 1991; 25: 685-90.

4 Brauninger G, Hood C, Worthen D. Sebaceous carcinoma of lid margin masquerading as cutaneous horn. Arch Ophthalmol 1973;90:380-4.

5 Shields JA, Font $R$. A meibomian gland carcinoma presenting as a lacrimal gland tumour. Arch Ophthalmol 1974; 92: 304-6.

6 Wright $P$, Collin JRO, Garner A. The masquerade syndrome. Trans Ophthalmol Soc UK 1981; 101: 244-50.

7 Cohen PR. Muir-Torre syndrome in patients with hematologic malignancies. Am f Hematol 1992; 40: 64-9.

8 Jakobiec F. Sebaceous adenoma of the eyelid and visceral malignancy. Am f Ophthalmol 1974; 78: 952-60.

9 Levin PS, Dutton JJ. A 20-year series of orbital exenteration. Am $\mathcal{F}$ Ophthalmol 1991; 112: 496-501.

10 Rao NA, Hidayat AA, McLean IW, Zimmerman LE. Sebaceous gland carcinoma of the ocular adnexa: a clinicopathologic study of 104 cases with five year follow-up data. pathologic study of 13: 113-22.

11 Del Cimmuto P, Del Papa U, Faccia M, Di Quirico R, Luciani M, Cellini G. Extra-ocular sebaceous carcinoma: report of a case. Chir Ital 1991; 43: 112-4.

12 Marx J. Cell death studies yield cancer clues. Science 1993; 259: 760-1.

\title{
Therapeutic ptosis with botulinum toxin in epikeratoplasty
}

\author{
Tim Freegard, Ian Mackie, Chad Rostron
}

\section{Department of Ophthalmology, St George's Hospital, London \\ T Freegard \\ I Mackie \\ C Rostron \\ Correspondence to: Mr Chad K Rostron, Department of Ophthalmology, St George's Hospital, Blackshaw Road, London SW17 0QT. \\ Accepted for publication 28 July 1993}

We present six cases in a consecutive series of patients undergoing epikeratoplasty, in whom a therapeutic ptosis induced with botulinum toxin was given at the time of surgery. All patients achieved primary re-epithelialisation of their lyophilised grafts within 8 days or less, and no case of secondary epithelial breakdown was observed, nor any significant complication from the botulinum toxin. In patients with keratoconus and eye rubbing, epikeratoplasty may be the preferred method of surgical treatment because it does not compromise the integrity of the globe. An additional advantage of the procedure is that it is not associated with graft rejection problems, ${ }^{1}$ which is particularly important for patients with mental handicap, Down's syndrome, and those who have poor compliance with treatment or follow up. However, graft failure in epikeratoplasty can occur through primary failure of re-epithelialisation of lyophilised graft tissue, or secondary epithelial breakdown. ${ }^{2}$ If epithelial defects are persistent, the lyophilised graft will suffer from stromal melting, and so the standard postoperative management includes close follow up, frequent application of topical ointment, and the use of bandage contact lenses, patching, etc. In patients with poor compliance, therapeutic ptosis induced by botulinum toxin could be a useful adjunct in the management of epikeratoplasty grafts, as it has been shown to be an effective treatment of epithelial defects in disease states. 